\title{
A Modified Removable Space Maintainer for Compromised Dentition of Children: A Case Series
}

\author{
Tanya Agarwal ${ }^{1}$, Nidhi Agarwal ${ }^{2}$
}

\begin{abstract}
Despite the attempt in prevention, premature loss of primary teeth remains to be a frequent problem in pediatric dentistry, resulting in disturbance of arch integrity and unfavorably affecting the alignment of permanent successors. Space maintainers (SMs) are distinctive appliances used for maintaining space created due to premature loss of primary teeth. But at times the dentition of children is so compromised that it prevents the use of a conventional SM. Introduced in this article is an innovative modified removable functional SM that offers several benefits over the traditional appliance. It is a straightforward and rapid method to fabricate but also omits band adaptation in uncooperative children and helps restore the functional harmony.
\end{abstract}

Keywords: Prosthesis retention, Removable partial denture, Space maintenance.

International Journal of Clinical Pediatric Dentistry (2020): 10.5005/jp-journals-10005-1843

\section{BACKGROUND}

Space maintenance is an integral part of preventive dentistry. Deprivation of arch length due to premature loss of primary teeth leads to well-documented complications, such as, individual tooth malpositions, overcrowding, ectopic eruption, impacted tooth, and deprived molar relationship. ${ }^{1}$ Conventional space maintainers (SMs) may be fixed or removable, active or passive, functional or non-functional. Fabrication of SMs requires certain clinical requisites that can vary according to the individual requirement. At times conventional SMs are not suitable and modification is required.

Thus, a modified removable SM was designed and applied in a series of cases in which the conventional SM could not be fabricated. The SM was customized to the existing clinical situation. They have been subsequently kept under observation, the maximum time being 12 months, and evaluated for their overall performance.

\section{Materials and Methods}

\section{Patient Case Selection}

Early loss of primary teeth, where the patient may require a functional SM.

An uncooperative child who is not willing for band adaptation.

\section{Design and Fabrication}

- Upper and lower impressions were taken and occlusion was established on the cast. Denture teeth were taken and trimmed to an appropriate size and placed on the edentulous area at correct occlusion.

- A wire of 21 gauge was used to make a modified type of labial bow in the attached gingiva area. An inverse " $U$ "-shaped bent was given in-between the central incisor so that the labial frenum was relieved.

- Conventional U-shaped loops were formed at the canine region, extending distally and bent occlusally from the primary/ permanent molar to end on the palatal or the lingual surface.
1,2Department of Pedodontics and Preventive Dentistry, Institute of
Dental Studies and Technologies, Modinagar, Uttar Pradesh, India Corresponding Author: Tanya Agarwal, Department of Pedodontics and Preventive Dentistry, Institute of Dental Studies and Technologies, Modinagar, Uttar Pradesh, India, Phone: +91 9997261979, e-mail: tanyapedo@gmail.com

How to cite this article: Agarwal T, Agarwal N. A Modified Removable Space Maintainer for Compromised Dentition of Children: A Case Series. Int J Clin Pediatr Dent 2020;13(6):722-724.

Source of support: Nil

Conflict of interest: None

- The wire served to provide strength and retention to the appliance.

- The base plate was formed of cold-cure acrylic resin to cover the labial as well as the palatal/lingual surface.

- So this formed a kind of a circummandibular/circummaxillary appliance (Fig. 1).

\section{Case Description}

An 8-year-old girl appeared to the Department of Pedodontics, with a chief complaint of pain in the lower right and left posterior tooth region. On clinical examination, deep carious lesion in respect to 84 and 85,75 and root stump in relation to 74 was discovered. Radiographs showed deep caries in relation to 75,84 , and 85 . And root stump i.r.t. 74. Due to the poor prognosis of the involved teeth extraction was planned followed by functional SMs (Fig. 2).

Postoperative instructions were given and the patient was recalled after 3,6 , and 12 months. No change in the fitting of the appliance was observed at 3 months, an eruption of 32 was observed in the given space of the SM and at 12 months eruption of 42 was observed in the given space with the appliance fitting well.

Three other cases were also given modified SMs, the results of which are mentioned in Table 1.

(0) Jaypee Brothers Medical Publishers. 2020 Open Access This article is distributed under the terms of the Creative Commons Attribution 4.0 International License (https://creativecommons.org/licenses/by-nc/4.0/), which permits unrestricted use, distribution, and non-commercial reproduction in any medium, provided you give appropriate credit to the original author(s) and the source, provide a link to the Creative Commons license, and indicate if changes were made. The Creative Commons Public Domain Dedication waiver (http://creativecommons.org/publicdomain/zero/1.0/) applies to the data made available in this article, unless otherwise stated. 

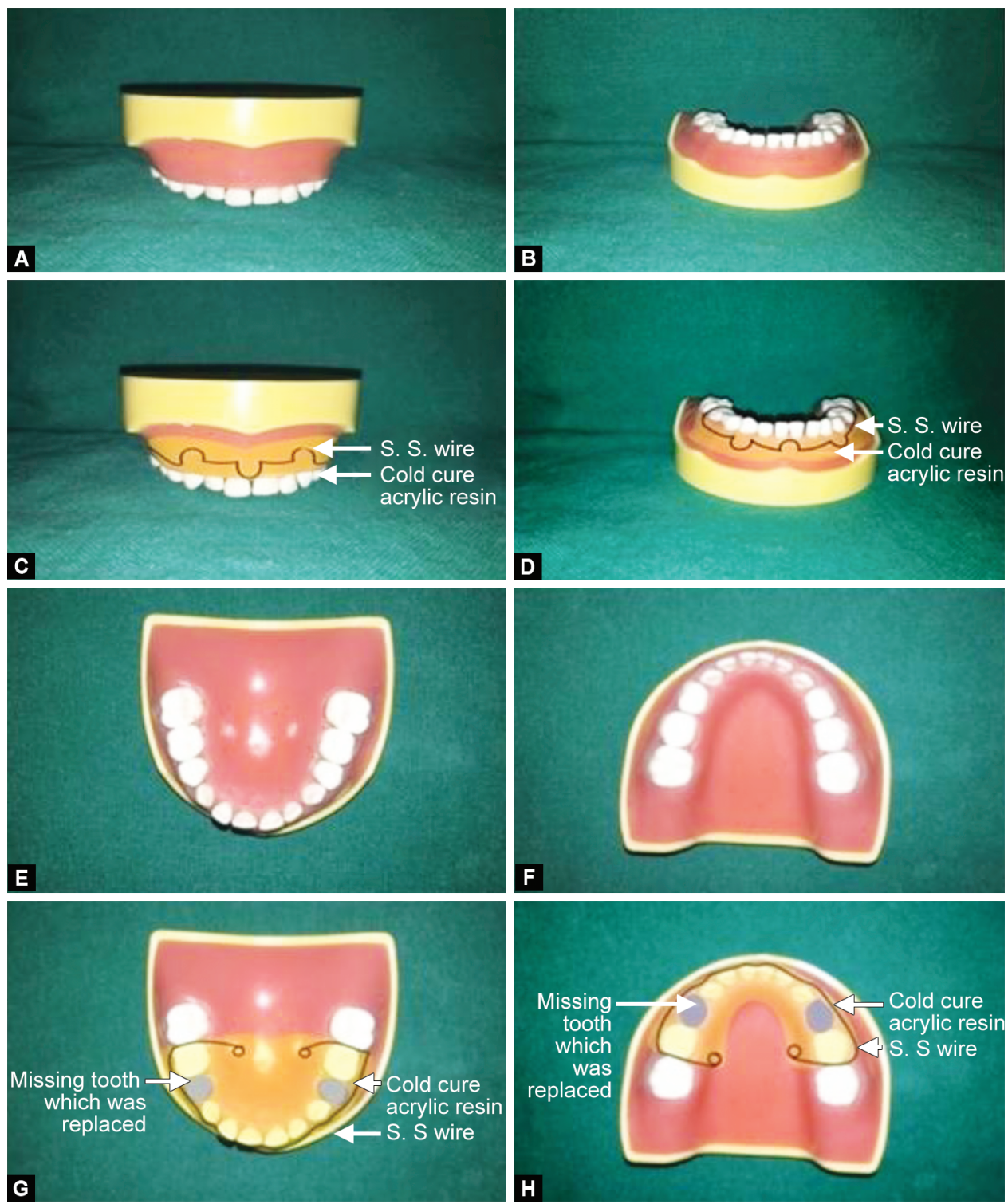

Figs $1 \mathrm{~A}$ and $\mathrm{B}$ : Concept of fabrication of the appliance
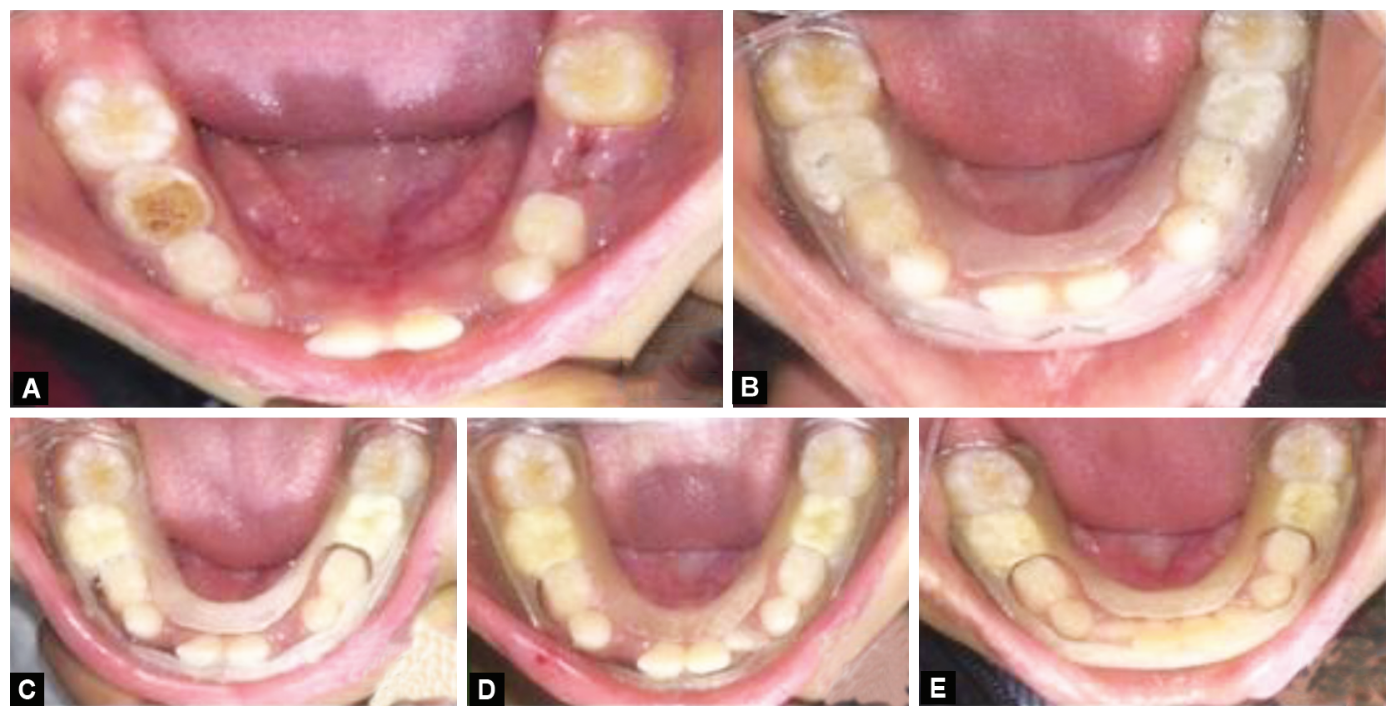

Figs 2A to E: (A) Preoperative view; (B) Immediate postoperative; (C) Follow-up-3 months; (D) Follow-up-6 months; (E) Follow-up-12 months 
Table 1: Detail and follow-up of the cases

\begin{tabular}{|c|c|c|c|c|c|c|}
\hline Patient name & Age (years) & Teeth missing & Treatment done & Follow-up-3 months & Follow-up-6 months & $\begin{array}{l}\text { Follow-up-12 } \\
\text { months }\end{array}$ \\
\hline Pranav & 72 months & 75 & $\begin{array}{l}\text { Unilateral functional } \\
\text { mandibular SM }\end{array}$ & Well-fitting appliance & $\begin{array}{l}\text { Missing } 85 \text {; addition } \\
\text { of } 85 \text { in the same SM }\end{array}$ & $\begin{array}{l}\text { Well-fitting } \\
\text { appliance }\end{array}$ \\
\hline Radhika & $7+4$ months & $74,75,84,85$ & $\begin{array}{l}\text { Bilateral functional } \\
\text { mandibular SM }\end{array}$ & Well-fitting appliance & $\begin{array}{l}\text { Eruption of } 44,45 \text { in } \\
\text { the space available }\end{array}$ & $\begin{array}{l}\text { Eruption of } 34 \text { in the } \\
\text { space available }\end{array}$ \\
\hline Tarun & $11+1$ months & 11,21 & $\begin{array}{l}\text { Bilateral functional } \\
\text { maxillary SM }\end{array}$ & Well-fitting appliance & Well-fitting appliance & $\begin{array}{l}\text { Well-fitting } \\
\text { appliance }\end{array}$ \\
\hline
\end{tabular}

\section{Discussion}

As young children are usually apprehensive, their extent of cooperation is limited, which leads to a demanding situation for the restoration of critically decayed primary teeth. ${ }^{2}$

Closure of space occurs during the first 6 months after tooth removal. It is best to place the SMs instantly following the extraction. Erupting premolars usually require $4-5$ months to progress through $1 \mathrm{~mm}$ of bone. ${ }^{3}$ Rao and Sarkar presented a study, which states that loss of space can take place by both mesial and distal movement of the adjacent teeth. ${ }^{4}$

No single case is related; hence, perception about the choice and type of SMs must be ruled by the presenting clinical scenario. ${ }^{5}$ An ideal appliance is one that would restore as much of the natural function of a tooth as possible following easy fabrication with the design of the appliance that is easily reproducible to all situations. The material should be inexpensive and have the longevity to remain in place till required and should not interfere with the normal eruption process. ${ }^{6}$

Removable SMs have certain advantages over fixed SMs such as being uncomplicated to clean, thus allowing better preservation of oral hygiene and may be used at the will of the patient although they may be broken or lost easily if not handled properly. This removable appliance, however, was manageable and easy to maintain hygienically.

In contrast, fixed appliances are less injurious to the oral tissues and are used uninterruptedly for a longer period. ${ }^{7}$ The soft deposits and inability of maintaining adequate hygiene, around the band might result in tissue irritation and hyperplasia. In some cases, obtaining retention gets difficult as none of the permanent teeth have erupted or are in various stages of eruption.

The present modification of the removable SMs has been found to fulfill all the criteria. The appliance was easy to fabricate and modify as per the individual need. Removable partial SM occasionally requires clasp adjustment and acrylic modification to maintain good retention and allow eruption of the underlying teeth, whereas this new design requires no clasp adjustment and therefore the problem of impingement is avoided. Most of the fixed appliances only serve to maintain the arch length, but frequently oversee the useful aspect of the primary tooth. ${ }^{6}$ This is not so with the present new design as it helps in restoring not only the missing teeth, esthetics but also the function. It is observed that generally, children do not tolerate ill-fitting appliances. However, retention of this appliance was easily obtained due to the design and the small children were quite compliant in wearing it all the time.

The main concern with the appliance was its relation to growth. But in the follow-up visits, it was seen that the appliance did not inhibit growth and ceased to fit whenever there was any change in the dentition. A new SM could be constructed easily. Judicious space maintenance benefits the child and may prevent future alignment and crowding problems.

Supervision and frequent follow-up of appointments at 3, 6, and 12 months showed that the modified removable SM had no deleterious effect on the growth.

\section{Conclusion}

The dispensed innovative design of the functional SM is simple and easy to fabricate. It requires less chairside time and hence increased acceptance by the children. The authors acclaim that the appliance is made-up routinely by dental specialists as it offers more benefits over conventional SMs.

\section{Clinical Significance}

This innovative modified removable functional SM offers several advantages like its hassle-free and rapid to fabricate, budget effective, and also omits band adaptation in uncooperative children and helps restore the functional harmony. There is also an added advantage that it does not hamper the growth and is a suitable appliance for maintaining the esthetics as well as function.

\section{References}

1. Srivastava N, Grover J, Panthri P. Space maintenance with an innovative "Tube and Loop" space maintainer (Nikhil appliance). Int J Clin Pediatr Dent 2016;9(1):86-89. DOI: 10.5005/jp-journals-10005-1340.

2. Parisotto TM, de Souza-e-Silva, Oliveira CS, et al. Prosthetic rehabilitation in a four-year-old child with severe early childhood caries: a case report. J Contempor Dent Pract 2009;10(2):90-97. DOI: 10.5005/jcdp-10-2-90.

3. Uddanwadiker R, Patil PG. Evaluation of the deformations on the jaw bone due to a band and loop, nance appliance and trans-palatal arch space-maintainers: a three-dimensional finite element analysis. Dentistry 2013;3:172.

4. Rao AK, Sarkar S. Changes in the arch length following premature loss of deciduous molars. J Indian Soc Pedod Prev Dent 1999;17(1): 29-32.

5. Pushpalatha C, Devi MM, Kamath PS, et al. A custom modified band and loop space maintainer- a case report. J Dent Oro-facial Res 2016;12(02):30-32.

6. Marwaha M, Bhat M, Nanda KDS. Building-up a smile in a 5-year-old child: a case report. Int J Clin Pediatr Dent 2012;5(2):151-154. DOI: 10.5005/jp-journals-10005-1156.

7. Subramaniam P, Babu G, Sunny R. Glass fiber reinforced composite resin as a space maintainer. A clinical study. J Indian Soc Pedod Dent 2008;26(Suppl S3):98-103. 